\title{
Thermo-Electric-Magnetic Hydrodynamics in Solidification: In Situ Observations and Theory
}

\author{
Y. FAUTRELLE $, 1,4$ J. WANG ${ }^{2}$ G. SALLOUM-ABOU-JAOUDE ${ }^{3}$ \\ L. ABOU-KHALIL ${ }^{3}$ G. REINHART ${ }^{3}$ X. LI, ${ }^{2}$ Z.M. REN ${ }^{2}$ \\ and H. NGUYEN-THI ${ }^{3}$
}

1.-SIMAP/EPM, Grenoble Institute of Technology, 1130 rue de la piscine BP 75 ENSEEG, 38402 St-Martin d'Heres, France. 2.-State Key Laboratory of Advanced Special Steel, Department of Material Science and Engineering, Shanghai University, Shanghai 200072, People's Republic of China. 3.-IM2NP UMR 7334, Aix Marseille Université \& CNRS, Campus Scientifique de SaintJérôme, Case 142, 13397 Marseille Cedex 20, France. 4.—e-mail: yves.fautrelle@simap.grenoble-inp.fr

Solidification of liquid metals contains all the ingredients for the development of the thermo-electric (TE) effect, namely liquid-solid interface and temperature gradients. The combination of TE currents with a superimposed magnetic field gives rise to thermo-electromagnetic (TEM) volume forces acting on both liquid and solid. This results in the generation of fluid flows, which considerably modifies the morphology of the solidification front as well as that of the mushy zone. TEM forces also act on the solid and cause both fragmentation of dendrite branches and a movement of equiaxed grains in suspension. These phenomena have already been unveiled by post-mortem analysis of samples, but they can be analyzed in more detail by using x-ray in situ and real-time observations. Here, we present conclusive evidence of all the aforementioned effects thanks to in situ observations of $\mathrm{Al}-\mathrm{Cu}$ alloy solidification under static magnetic field.

\section{INTRODUCTION}

The use of magnetic fields is a widespread technique to master the flow patterns in the melt during solidification of electrically conducting materials, and then to obtain the desired properties of the grown material, leading to improvement of the process performance and better-quality products. ${ }^{1-3}$ One of the main advantages of this technique is to be contactless, which prevents alloy contamination and avoids any risk when using a brittle crucible. The role played by a magnetic field during directional solidification is quite diverse. ${ }^{4}$ A non-permanent magnetic field may be utilized to increase melt stirring, which may be useful for producing either a more uniform melt by a strong mixing in the liquid phase or a shear flow to induce grain refinement effects during metal casting. Alternatively, a permanent magnetic field can be used in order to dampen or eliminate convection during solidification, which can reduce temperature fluctuations and improve uniformity of compositions and mechanical properties.
The actions of a magnetic field on a conductive melt are due to the Lorentz force, a volume force generated by the interaction between the induced electric current in the liquid phase and the applied magnetic field. ${ }^{4}$ However, Shercliff ${ }^{5}$ pointed out that a static magnetic field can also produce flows in the melt during the metallurgy process caused by the interaction of the magnetic field with electric currents produced by variations of the Seebeck coefficients at the solid-liquid interface, i.e., the socalled thermo-electric (TE) effect. Such flows have been well studied in the case of the solidification of metallic alloys ${ }^{6-8}$ and in the context of pumping or stirring liquid metal coolants in nuclear reactors. ${ }^{9}$ Another important aspect is the existence of the thermo-electromagnetic (TEM) forces, created by the interaction between the electric current generated by the TE effect in the vicinity of the liquidsolid interface submitted to a temperature gradient (Thomson-Seebeck effect) and the static magnetic field. ${ }^{5,7}$ From a general point of view, TE currents appear in a liquid metal (1) when there exist 
temperature gradients (Thomson effect), and (2) when the solid-liquid interface is submitted to a temperature gradient $G=\nabla T$ which is not perpendicular to the solidification front.

The aim of this paper is first to present some recent experimental evidence of the TEM forces obtained during directional solidification of $\mathrm{Al}-\mathrm{Cu}$ alloys using in situ observations by means of synchrotron X-radiography. ${ }^{10-14}$ A quantitative comparison of experimental data with a theoretical model and numerical simulations is performed, which shows a very good agreement.

\section{DESCRIPTION OF THE MAIN THERMOELECTRIC (TE) EFFECTS}

During the propagation of the solidification front, several effects appear at the solid-liquid interface as well as in the two phases. A Peltier-Seebeck effect occurs at the interface between two media having different absolute TE powers, whereas a Thomson effect takes place in the solid or liquid bulk. The TE effect occurs in metallic materials when they are submitted to a temperature gradient $G=\nabla T$. The TE effect produces an electric field in the medium bulk. Then, using Ohm's law, the electric current density in each phase may be written as follows:

$$
\begin{aligned}
\mathbf{j}_{i}= & -\sigma_{i}\left(\nabla V+S_{i} \nabla T\right), \quad i=l, s, \text { respectively } \\
& \text { in the liquid and in the solid }
\end{aligned}
$$

In Eq. 1, $V$ denotes the electric scalar potential and $\sigma$ the electrical conductivity of solid or liquid phase. The second term of the r.h.s. in Eq. 1 accounts for the contribution of the TE current via the absolute TE power $S_{i}$ of the materials. The electric current created by the interaction between the motion and the applied magnetic field is neglected in Eq. 1. When a static magnetic field is superimposed on the system, it interacts with the $\mathrm{TE}$ currents to create electromagnetic body forces $\mathbf{F}=\mathbf{j}_{i} \times \mathbf{B}$. For more details, the reader is referred to a recent review by Fautrelle et al. ${ }^{15}$

TEM forces act on both the liquid metal and the solid. During the solidification, several types of phase and solid morphology may be encountered in various regions, namely liquid and solid phases, columnar structures which are found in a mushy zone and equiaxed grains which nucleate ahead of the columnar front. Each of the zones gives rise to specific phenomena, which will be addressed hereafter.

At the boundary between two media, e.g., liquid and solid, the interface behaves like a battery, and a $\mathrm{TE}$ current is generated from the following conditions at the boundary: $:^{5}$

$$
\left[\left(\frac{\mathbf{j}_{s}}{\sigma_{s}}-\frac{\mathbf{j}_{l}}{\sigma_{l}}\right)+\left(S_{s}-S_{l}\right) \nabla T\right] \cdot \mathbf{t}=0
$$

$\mathbf{t}$ being a vector tangent to the interface.
In solidification conditions, all the ingredients to produce a Peltier-Seebeck effect are present in the system. The boundary condition (Eq. 2) indicates that the existence of TE currents depends on three main conditions: ${ }^{15}$

- the liquid and solid absolute TE powers must be different $\left(S_{\mathrm{s}}-S_{\mathrm{l}}\right) \neq 0$,

- there exists a temperature gradient in the vicinity of the interface,

- the temperature gradient must not be perpendicular to the interface, $\nabla T . \mathbf{t} \neq 0$.

The absolute TE powers of usual metallic alloys are generally weak, of the order of $10^{-6} \mathrm{~V} / \mathrm{K} .^{5}$ However, in the presence of strong magnetic fields, the influence of TEM effects becomes significant owing to the large magnitude of the Lorentz forces, the order of magnitude of which is:

$$
\mathbf{F}_{\mathrm{TE}}=\mathbf{j} \times \mathbf{B} \approx \mathrm{O}(\sigma S|\nabla T| B) .
$$

Let us consider, for example, a liquid $\mathrm{Al}-\mathrm{Cu}$ aluminium alloy, which will be used in the experiments hereafter. Let us use the following typical numerical values, $\sigma=4 \times 10^{6} \mathrm{~S} / \mathrm{m}, S=10^{-6} \mathrm{~V} / \mathrm{K}$, $\rho=2.6 \times 10^{3} \mathrm{~kg} / \mathrm{m}^{3},|\nabla T|=2 \times 10^{3} \mathrm{~K} / \mathrm{m}, B=0.08$ T. ${ }^{12}$ From Eq. 3 , the estimate of the TEM forces, equal to $640 \mathrm{~N} / \mathrm{m}^{3}$, is quite large even for a moderate magnetic field value. Therefore, significant effects may be expected.

In solidification conditions, the solid and the liquid phases usually have different TE powers. One of the necessary conditions for the development of TE effects is fulfilled. Thus, PeltierSeebeck effects are localized mostly near the solidification front and play a major role in solidification under static magnetic fields. The measurements achieved by Kaldre et al. ${ }^{16}$ clearly put forth a jump of the absolute TE power near the liquid-solid interface, showing a clear difference between $S_{s}$ and $S_{l}$. They also showed that the sign of $\left(S_{s}-S_{l}\right)$ depends not only on the nature of the metal but also on the composition in the case of alloy.

\section{EXPERIMENTAL METHODOLOGY}

\section{Solidification Experiments with In Situ X-ray Radiography}

The in situ and real-time observations of the equiaxed grain motion during solidification of $\mathrm{Al}-\mathrm{Cu}$ under a static magnetic field have been carried out by means of synchrotron x-ray radiography. To minimize the grain sinking phenomena, solidifications were conducted on Al- 10 wt. $\% \mathrm{Cu}$ alloys for which the grain density is close to or slightly larger than the surrounding liquid. ${ }^{19}$ Several series of solidification experiments were carried out with three different cooling rates $(R=1 \mathrm{~K} / \mathrm{min}, 2 \mathrm{~K} / \mathrm{min}$ and $4 \mathrm{~K} / \mathrm{min}$ ), and a varying temperature gradient 


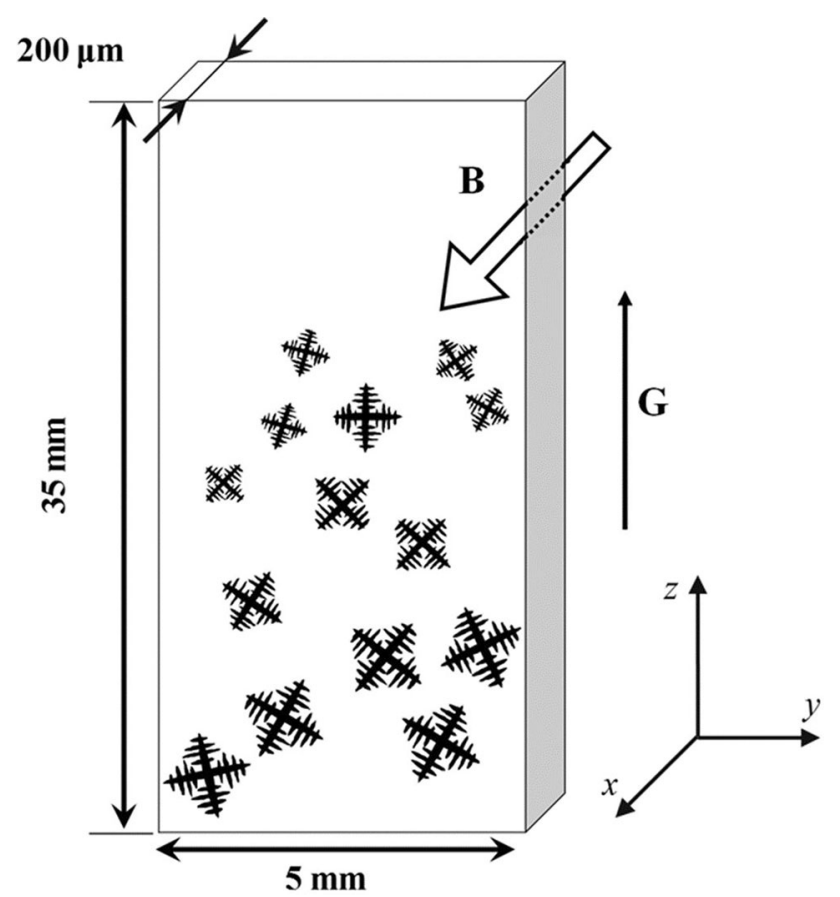

Fig. 1. The sample geometry (in the case of equiaxed growth), with the direction of the magnetic field (outgoing) and the temperature gradient.

$G$, decreasing from $20 \mathrm{~K} / \mathrm{cm}$ to nearly zero (close to isothermal conditions). In this review paper, emphasis is laid on the experiment at $R=2 \mathrm{~K} / \mathrm{min}$.

The experiments were carried out on a beamline BM05 at the European Synchrotron Radiation Facility (ESRF; Grenoble, France). The Al-Cu alloy samples were melted/solidified vertically inside a Bridgman furnace (described in more detail in Nguyen-Thi et al. ${ }^{17}$ ) The applied thermal gradient $G$ (oriented along the $z$-direction) was imposed by two separated heating elements and the solidification was controlled by applying the same cooling rate $R$ on the two heating elements. The sheet-like $\mathrm{Al}-\mathrm{Cu}$ samples studied were $35 \mathrm{~mm}$ in length, $-6 \mathrm{~mm}$ in width and $200-300 \mu \mathrm{m}$ in thickness, sandwiched between graphite foils and molybdenum diaphragms. The static magnetic field was generated by a cubic neodymium magnet (50 $\mathrm{mm} \times 50 \mathrm{~mm} \times 50 \mathrm{~mm}$ ), which was fixed close to the Bridgman furnace and imposed a permanent magnetic field $B$, of $0.08 \mathrm{~T}$ at the location of the sample. ${ }^{10}$ Before the solidification experiment, the direction of the magnetic field was set perpendicular to the main plane of the sample $(y-z$ plane $)$ and parallel to the beam ( $x$-direction). Two opposite directions of the static magnetic field were applied (Fig. 1), outgoing and incoming, from the radiographs.

The solid-liquid interface was visualized by synchrotron x-ray radiography: the main surface of the sample was set perpendicular to the incident monochromatic $\mathrm{x}$-ray beam. Absorption is the main source of the image contrast and largely depends on the atomic number of the elements and the solute content. In our experiments, the x-ray energy was adjusted to $17.5 \mathrm{keV}$ for thin samples $(\sim 200 \mu \mathrm{m})$ and to $19 \mathrm{keV}$ for thick ones, which are appropriate values for hypoeutectic $\mathrm{Al}-\mathrm{Cu}$ alloys. In all the radiographs, the aluminum solid microstructures appear in white and the copper-rich liquid in dark gray. The optics were chosen to obtain a large field of view (10 $\mathrm{mm} \times 6 \mathrm{~mm})$, which is essential in these kinds of studies to visualize and follow the motion of equiaxed grains over a long distance. The spatial resolution was then imposed by the optics with pixel size $7.46 \mu \mathrm{m} \times 7.46 \mu \mathrm{m}$ or $5.83 \mu \mathrm{m} \times 5.83 \mu \mathrm{m}$. The details of this synchrotron x-ray radiography setup can be found in Ref. 18.

\section{Grain Motion Characterization Based on In Situ and Real-Time Observation}

In order to conduct a comparison with the analytical model or numerical simulations, a quantitative analysis of the experiments has been carried out. The measurements of two key parameters were performed, which are expected to depend on the TEM and gravity forces, namely (1) the initial deviation angle between the grain trajectory and the downward vertical direction, and (2) the grain velocity, $U(\mathrm{t})$, during its motion, which depends on the grain diameter, $d_{\mathrm{S}}(\mathrm{t})$. For this latter measurement, a critical issue was that the shape of a dendritic grain is obviously very complex and far from a spherical solid in three dimensions or a circle in two dimensions. Therefore, we used an "equivalent-disk diameter" $d_{\mathrm{S}}(\mathrm{t})$, which is defined as the diameter of the disk that would have the same area of the grain under consideration.

\section{EQUIAXED GRAIN DEFLECTION}

The in situ and real-time observations of the equiaxed grain motion during solidification of $\mathrm{Al}-\mathrm{Cu}$ under a static magnetic field have been carried out by means of synchrotron x-ray radiography. To minimize the grain sinking phenomena, solidifications were conducted on $\mathrm{Al}-10 \mathrm{wt} . \% \mathrm{Cu}$ alloys.

The experiments clearly displayed a deflection of equiaxed grains in a direction perpendicular both to the magnetic field and the temperature gradient (Fig. 2). To ease the grain motion analysis, a simple image processing was used, which consisted of taking the maximum intensity of successive radiographs to create a single image. ${ }^{13}$ As the $\alpha$-Al grains appeared in white in the radiographs, this image processing revealed the successive positions of the grains and thus their trajectories (yellow-white arrows in Fig. 2). From the radiographs, the angle deflections $\theta$, between the trajectory of the equiaxed grain and gravity direction were measured for the different temperature gradients and for the two opposite direction of the magnetic field. Figure $3 a$ shows that the higher the temperature gradient, the 


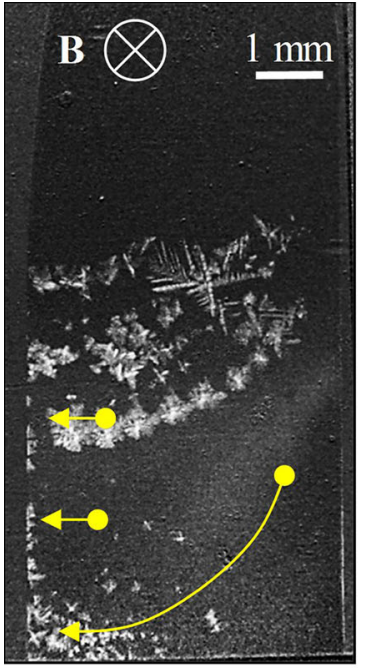

(a) $G=20 \mathrm{~K} / \mathrm{cm}$

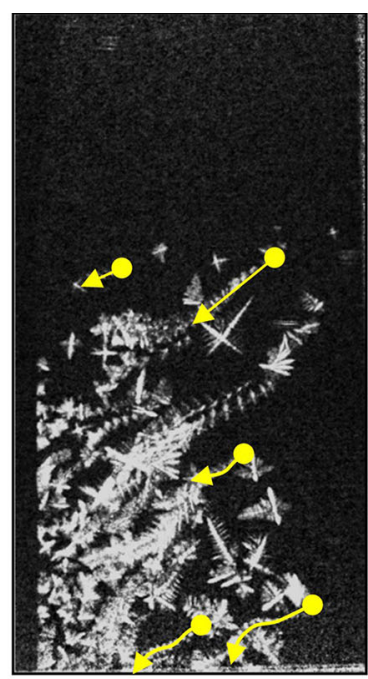

(b) $G=10 \mathrm{~K} / \mathrm{cm}$

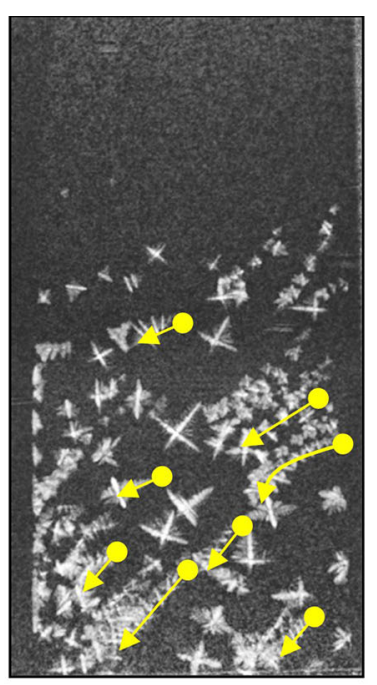

(c) $G=5 \mathrm{~K} / \mathrm{cm}$

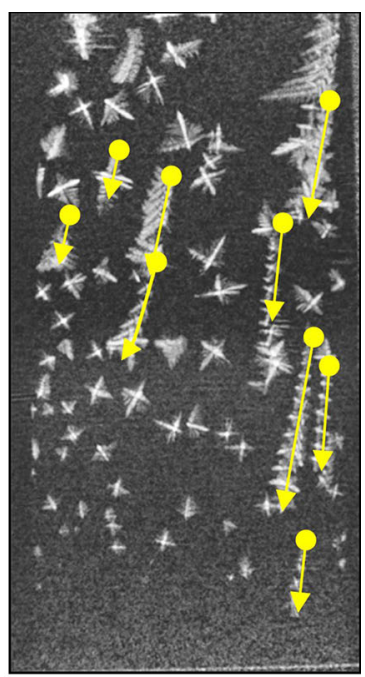

(d) $G \sim 0 \mathrm{~K} / \mathrm{cm}$

Fig. 2. Maximum exposure intensity of successive radiographs showing the equiaxed solidification experiments of Al-10 wt.\%Cu (cooling rate $R=2 \mathrm{~K} / \mathrm{min}$ ) under a $0.08-\mathrm{T}$ static magnetic field at different temperature gradients. The trajectories of few grains are represented by yellowwhite arrows (Color figure online).

larger the deflection angle $\theta$, in agreement with Wang-Fautrelle model, ${ }^{12}$ which predicts a TEM force perpendicular both to the magnetic field and the temperature gradient. For the same solidification conditions, but with the opposite direction of the magnetic field, the direction of the grain motion is simply reversed, from the left side to the right side of the sample, and the angle deviation sign changes (Fig. 3a).

The deflection velocity versus the grain diameter was measured and compared to Wang-Fautrelle model achieved in the case of a spherical solid grain (Fig. 3b). Figure 3b shows a satisfactory agreement between the measured deflection velocities for a temperature gradient $G=5 \mathrm{~K} / \mathrm{cm}$ and the computed ones, when taking into account the confinement effect $^{20}$ and the grain morphology. ${ }^{21}$ From this comparison, it appears that the model overestimates the grain velocity, which suggests that additional effects due to TEM phenomena have to be included in the model, such as TEM force acting on the liquid phase surrounding the grain.

\section{DENDRITE FRAGMENTATION}

As mentioned before, TEM forces act on the solid phase so that they cause stresses inside the dendrite microstructure and might also promote dendrite fragment detachment, as discussed by Reinhart et al. ${ }^{22}$ The branches of the dendrites themselves are subjected to a TEM volume force comparable to that exerted on a free grain as discussed in the previous paragraph. Several series of experiments were conducted on $\mathrm{Al}-4 \mathrm{wt} . \% \mathrm{Cu}$ alloy, at a temperature gradient $G=30 \mathrm{~K} / \mathrm{cm}$ and for low cooling rates in order to achieve dendritic columnar growth. $^{12}$ The static magnetic field, $B=0.08 \mathrm{~T}$, was generated in the same manner as for the experiments on equiaxed growth, with a permanent magnet fixed close to the Bridgman furnace. The in situ observations showed that, during the dendritic columnar growth, many fragments were detached from the main dendrite and moved approximately along the horizontal direction $(y$ direction). Figure 4 displays two sequences of four successive images of the motion of fragments, for the two opposite directions of the permanent magnetic field. The mean paths of the fragment are indicated by the white dotted lines. It must be stressed that, in these experiments, the dendrite fragmentations occur only when the magnetic field was present, which means that this phenomenon can be attributed to TEM forces.

To analyze the detachment mechanism, let us assume that the TEM force acting on a dendrite branch of diameter $d$ is comparable to that exerted on an equiaxed grain of the same external size. The TEM force was calculated by COMSOL Multiphysics. For $d=200 \mu \mathrm{m}$, the net TEM force is equal to $0.5 \times 10^{-9} \mathrm{~N}$. Note that, in the case of a spherical grain of the same diameter, the TEM force is $3.0 \times 10^{-9} 9 \mathrm{~N}$. The tensile elastic limit of an aluminum-nickel alloy trunk ranges between $0.02 \mathrm{MPa}$ and $0.3 \mathrm{MPa}{ }^{22}$ Thus, the tensile limit for a trunk of radius $r=1 \mu \mathrm{m}$ ranges between $6.3 \times 10^{-8} \mathrm{~N}$ and $0.94 \times 10^{-6} \mathrm{~N}$. In the present experiments, the magnetic field is quite moderate, and it is likely that the TEM force is not large enough to be able to detach pieces of dendrite from their trunks. The detachment phenomenon, which has been observed during our in situ experiments, is most likely due to the significant liquid motion generated by the TEM forces acting on the liquid around the dendrite. ${ }^{23,24}$ Baltaretu et al. ${ }^{23}$ showed that strong TEM flows up 

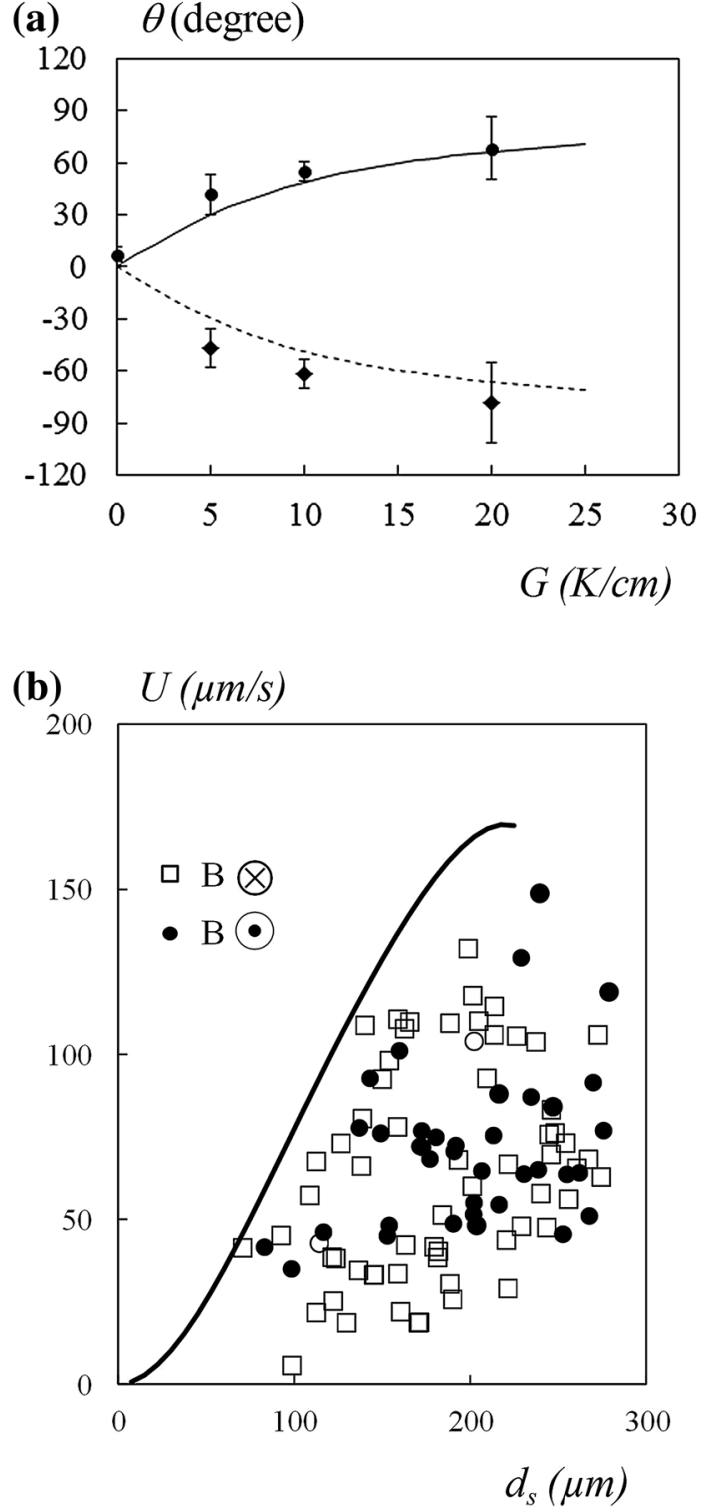

Fig. 3. (a) Variation of the deflection angle $\theta$ as a function of temperature gradient for both opposite direction of the magnetic field (cooling rate $R=2 \mathrm{~K} / \mathrm{min}$ ). The solid and dashed lines are the calculated angles from Wang-Fautrelle model, respectively. The error bars are the standard deviation over almost 10 grains for each experiment, (b) the grain velocity as a function of grain diameter for a temperature gradient of $G=5 \mathrm{~K} / \mathrm{cm}$. The symbols represent experimental measurements of about 10 grains, nucleating almost in the same region of the sample. The solid line is the theoretical prediction from Wang-Fautrelle model, taking both into account for the wall correction and the grain morphology.

to $1.4 \mathrm{~mm} / \mathrm{s}$ may be generated around a $50-\mu \mathrm{m}-$ radius spherical aluminum particle in a $0.08 \mathrm{~T}$ transverse magnetic field under a $30-\mathrm{K} / \mathrm{cm}$ temperature gradient. These fluid flows could locally increase the liquid composition in the copper and then yield to the remelting of the secondary arm neck, which is the constricted region at the base where the secondary arm joins the primary dendrite trunk. Nevertheless, the direct TEM force acting on the solid may contribute to the final dendrite arm detachment, when the neck diameter decreases below a critical value.

\section{CHANNELING: FLOW IN THE MUSHY ZONE}

During several solidification experiments under a static magnetic field and for high-temperature gradients $(G=20 \mathrm{~K} / \mathrm{min}$ and $10 \mathrm{~K} / \mathrm{cm})$, large liquid channels were observed to form and remained visible in the final grain structure (Fig. 5). For the outgoing magnetic field (Fig. 5a), the channels are directed from the bottom-left side towards the upper-right side and create liquid layers that cross the whole width of the sample. It is worth noting that such channels were never observed in experiments without magnetic field and that they are less pronounced when decreasing the temperature gradient and increasing the cooling rate. In addition, by inverting the orientation of the static magnetic field (Fig. 5b), these segregated channels also changed direction and were oriented from the bottom-right side to the upper-left side of the sample.

The formation of these liquid channels can be attributed to forced TEM convective flows induced by the application of the static magnetic field. These fluid flows act on the distribution of solute both in the melt and in the mushy zone. For instance, Yasuda et al. reported in situ observations that fluid flow can transport dendrite fragments ahead of the columnar front during solidification of a $\mathrm{Al}-\mathrm{Cu}$ alloy. ${ }^{25}$ Previously, Lehmann et al. ${ }^{26}$ showed experimental evidence for TEM convection and observed that the effect of the TE Lorentz force can dampen or enhance the convection depending on the magnitude of the magnetic field and the temperature gradient. During upward solidification, when the solute is denser than the solvent, solute accumulation in depressed regions of the solidification front occur and leads to strong radial segregations (see, for example, Bogno et al. ${ }^{27}$ ) In our experiments, where the magnetic field is perpendicular to the solidification direction, TEM convection will form at the solidification front, but also within the mushy zone, and induce recirculation loops in the melt and inside the mushy zone. In the case of an incoming static magnetic field, the recirculation loops will cause heavier solute to be transported from the right side to the left side (Fig. 6). In both cases, the concentration of the solute increases from one side of the sample to the other side according to the magnetic field direction.

The aforementioned phenomenon may be explained by considering the TE effects in the mushy zone. This mushy zone is similar to a porous medium consisting of solid dendrite surrounded by liquid. In this region, the density of solid-liquid interface is important. As a result, a Peltier effect is developed at the scale of the dendrite branches, resulting in TE currents, globally parallel to the 

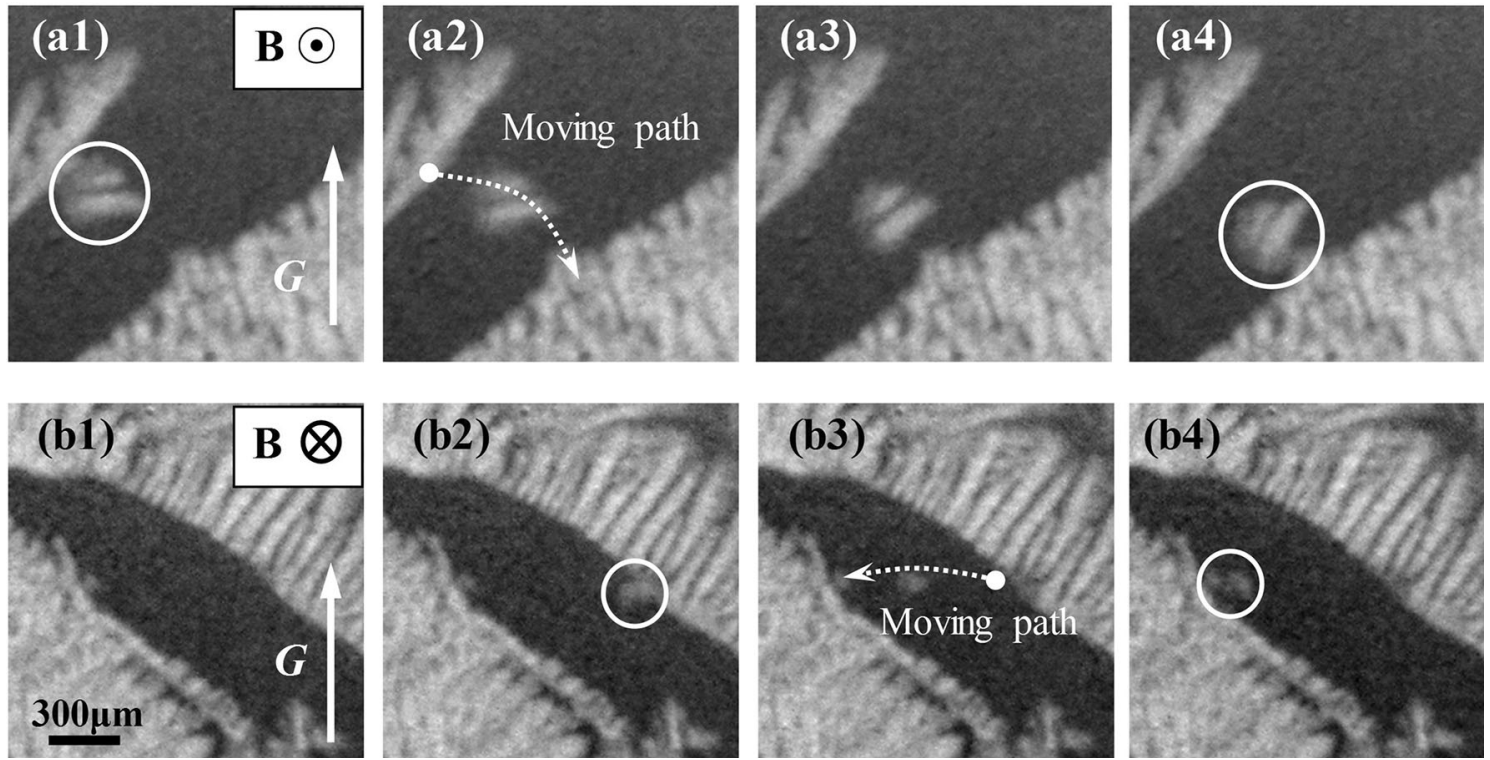

Fig. 4. Examples of the detachment of dendrite fragments during directionally solidifying $\mathrm{Al}-4 \mathrm{wt} . \% \mathrm{Cu}$ alloys under transverse magnetic fields $(B=0.08 \mathrm{~T})$ : (a1-a4) outgoing magnetic field and (b1-b4) ingoing magnetic field ( $G=30 \mathrm{~K} / \mathrm{cm}, R=2 \mathrm{~K} / \mathrm{min})$. The time interval between two successive radiographs is $1.9 \mathrm{~s}$.

(a)
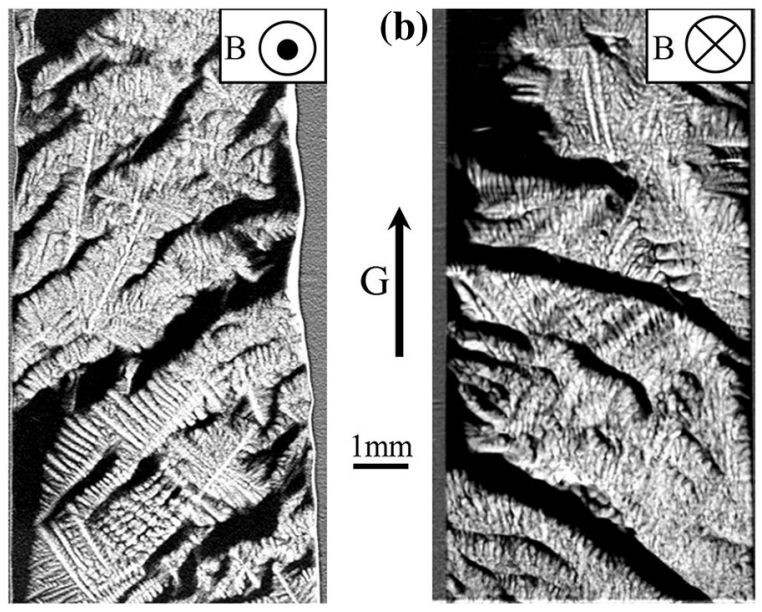

Fig. 5. Radiographs showing the microstructure of $\mathrm{Al}-10 \mathrm{wt} . \% \mathrm{Cu}$ samples solidified under static magnetic field, at a temperature gradient $G=20 \mathrm{~K} / \mathrm{cm}$ for (a) outgoing magnetic, $R=2 \mathrm{~K} / \mathrm{min}$ and (b) incoming magnetic field, $R=1 \mathrm{~K} / \mathrm{min}$.

temperature gradient. When a transverse $B$ magnetic field is applied, its interaction with the TE currents produces an electromagnetic force in the liquid which is also transverse, but perpendicular to both the temperature gradient and to $B$. This electromagnetic force density $F_{\text {mush }}$ was estimated using a simple model of dendrite consisting of columns parallel to the temperature gradient. ${ }^{28}$ Its expression is:

$$
\mathbf{F}_{\text {mush }}=-\sigma_{l}\left(S_{l}-S_{s}\right) \frac{\sigma_{s} f_{s}}{f_{l} \sigma_{l}+f_{s} \sigma_{s}} \nabla T \times \mathbf{B}
$$

where $f_{s}$ and $f_{l}$ denote, respectively, the solid and liquid fraction in the mushy zone.

The transverse TEM force drives a significant transverse flow in the mushy zone, which by continuity generates an upward motion of soluteenriched liquid, as illustrated in Fig. 6a. That flow is able to produce remelting of the dendrites and accordingly tilted channels. Note that the channeling phenomenon was also observed by post-mortem analysis in other directional solidification experiments under a static magnetic field. ${ }^{29}$

\section{CONCLUSION}

This paper provides in situ and real-time observations of solidifications of $\mathrm{Al}-\mathrm{Cu}$ alloys (4 and 10 wt.\%) under a weak static magnetic field $(B=0.08$ $\mathrm{T})$. Both equiaxed and columnar microstructures were analyzed and the effects of TEM forces were clearly explained and interpreted by magnetohydrodynamics concepts. The experimental results show that equiaxed grains were forced to move approximately along a direction perpendicular to both the temperature gradient and the magnetic field, which confirms the action of the TEM force on solid particles. A satisfactory agreement was obtained with Wang-Fautrelle model established for a solid spherical grain, taking into account the corrections of wall confinement and grain morphology. The remaining discrepancy may be attributed to either the TEM force acting on the liquid around the dendrite that is neglected in the model or the complex grain morphology that may change the net TEM force acting directly on the solid. 
(a)

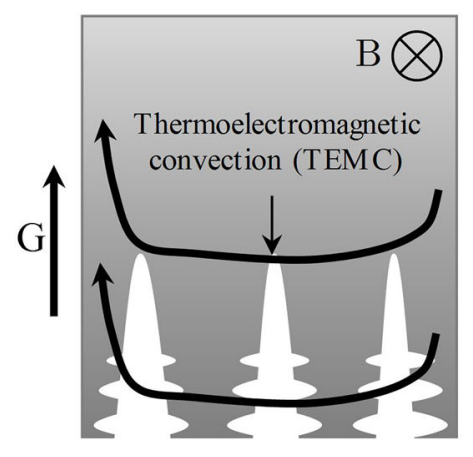

(b)

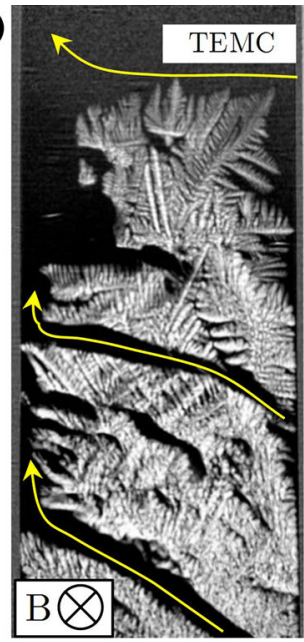

(c)

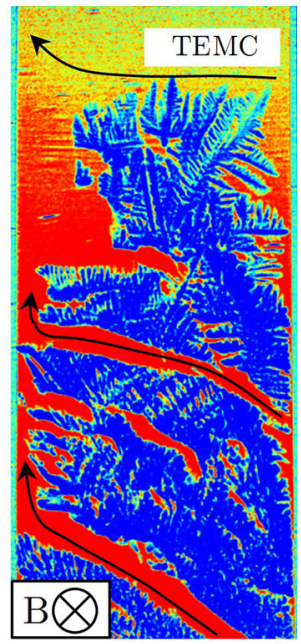

Fig. 6. (a) The thermo-electromagnetic convection (TEMC) during the solidification under an incoming static transverse magnetic field and the TEM force in the mushy zone; (b) radiograph of $\mathrm{Al}-10 \mathrm{wt} . \% \mathrm{Cu}$ solidified at a temperature gradient $G=20 \mathrm{~K} / \mathrm{cm}$ and for a cooling rate $R=1 \mathrm{~K} /$ min showing the segregated channels induced by TEMC; and (c) radiograph showing the accumulation of the solute (red/gray) on the left side of the sample by the TEMC (Color figure online).

During dendritic columnar growth, dendrite fragmentations were observed. After their detachment, the dendrite fragments moved in the same manner as those equiaxed under the action of TEM forces. The dendrite fragmentation observed in our experiment were most likely due to the combination of a remelting effect induced by the TEM convection of $\mathrm{Cu}$-enriched liquid and the TEM force acting on the weak part of the fragment.

Finally, a channeling phenomenon was also unveiled, due to the significant TEM convection in the mushy zone which induced recirculation loops in the melt and inside the mushy zone. These recirculation loops caused the heavier solute to be transported from one side to the other side of the sample and create large liquid channels in the final grain structures that cross the whole width of the sample.

It is noticeable that TEM effects have a strong influence on solidification of metallic alloys even for moderated magnetic field values. Several interesting phenomena were put forward, but some others have not reported here, like the flattening of the liquid-solid interface, ${ }^{12}$ and an increase of the number of dislocations. ${ }^{15}$

\section{ACKNOWLEDGEMENTS}

Part of this work was partially funded by the European Space Agency (XRMON MAP Contract Number 20288/06/NL/VJ), the French National Space Agency (CNES, Contract No. 160483/00) and the EC (EXOMET Project NMP.2011.4.0-1).

\section{OPEN ACCESS}

This article is distributed under the terms of the Creative Commons Attribution 4.0 International License (http://creativecommons.org/licenses/by/4.0/ ), which permits unrestricted use, distribution, and reproduction in any medium, provided you give appropriate credit to the original author(s) and the source, provide a link to the Creative Commons license, and indicate if changes were made.

\section{REFERENCES}

1. D.T.J. Hurle and R.W. Series, Use of a magnetic field in melt growth (Amsterdam: North Holland, 1994).

2. P.A. Davidson, Annu. Rev. Fluid Mech. 31, 273 (1999).

3. P. Rudolph, J. Cryst. Growth 310, 1298 (2008).

4. R. Moreau, Magnetohydrodynamics, Kluwer Publications: Dordrecht, The Netherlands (1990).

5. J.A. Shercliff, J. Fluid Mech. 91, 231 (1979).

6. P. Dold, F.R. Szofran, and K.W. Benz, J. Cryst. Growth 291, 1 (2006).

7. P. Lehmann, R. Moreau, D. Camel, and R. Bolcato, Acta Mater. 46, 4067 (1998).

8. X. Li, A. Gagnoud, Z. Ren, Y. Fautrelle, and R. Moreau, Acta Mater. 57, 2180 (2009).

9. M.A. Jaworski, T.K. Gray, M. Antonelli, J.J. Kim, C.Y. Lau, M.B. Lee, M.J. Neumann, W. Xu, and D.N. Ruzic, Phys. Rev. Lett. 104, 094503 (2010).

10. J. Wang, Y. Fautrelle, Z.M. Ren, X. Li, H. Nguyen-Thi, N. Mangelinck-Noel, G. Salloum Abou Jaoude, Y.B. Zhong, I. Kaldre, A. Bojarevics, and L. Buligins, Appl. Phys. Lett. 101, 251904 (2012).

11. J. Wang, Z.M. Ren, Y. Fautrelle, X. Li, H. Nguyen-Thi, N. Mangelinck-Noel, G. Salloum Abou Jaoude, Y.B. Zhong, I. Kaldre, and A. Bojarevice, J. Mater. Sci. 48, 213 (2012). https://doi.org/10.1007/s10853-012-6730-6.

12. J. Wang, Y. Fautrelle, Z.M. Ren, H. Nguyen-Thi, G. Salloum-Abou-Jaoude, G. Reinhart, N. Mangelinck-Noel, X. Li, and I. Kaldre, Appl. Phys. Lett. 104, 121916 (2014).

13. G. Salloum-Abou-Jaoude, J. Wang, L. Abou-Khalil, G. Reinhart, Z.M. Ren, N. Mangelinck-Noel, X. Li, Y. Fautrelle, and H. Nguyen-Thi, J. Cryst. Growth 417, 25 (2015).

14. J. Wang, Y. Fautrelle, H. Nguyen-Thi, G. Reinhart, H. Liao, X. Li, Y. Zhong, and Z.M. Ren, Met. Mat. Trans A 47A, 1169 (2016).

15. Y. Fautrelle, J. Wang, D. Du, X. Li, and Z.M. Ren, in Solidification processing of metallic alloys under external fields, ed. D. Eskin and J. Mi (Berlin: Springer, 2017).

16. I. Kaldre, Y. Fautrelle, J. Etay, A. Bojarevics, and L. Buligins, Mod. Phys. Lett. B 25-10, 731 (2011). 
17. H. Nguyen-Thi, H. Jamgotchian, J. Gastaldi, J. Härtwig, T. Schenk, H. Klein, B. Billia, J. Baruchel, and Y. Dabo, J. Phys. D Appl. Phys. 36, A83 (2003).

18. T. Schenk, H. Nguyen Thi, J. Gastaldi, G. Reinhart, V. Cristiglio, N. Mangelinck-Noël, H. Klein, J. Härtwig, B. Grushko, B. Billia, and J. Baruchel, J. Cryst. Growth 275, 201 (2005).

19. S. Ganesan and D.R. Poirier, Metall. Mater. Trans. A Phys. Metall. Mater. Sci. 18A, 721 (1987).

20. H. Faxén, Ann. Phys. 373, 89 (1922).

21. R. Zakhem, P.D. Weidman, and H.C. Degroh, Metall. Mater. Trans. A Phys. Metall. Mater. Sci. 23, 2169 (1992).

22. G. Reinhart, A. Buffet, H. Nguyen-Thi, B. Billia, H. Jung, N. Mangelinck-Noel, N. Bergeon, T. Schenk, J. Hartwig, and J. Baruchel, Metall. Mater. Trans. A-Phys. Metall. Mater. Sci. 39, 865 (2008).
23. F. Baltaretu, J. Wang, S. Letout, Z.M. Ren, X. Li, O. Budenkova, and Y. Fautrelle, Magnetohydrodynamics 51, 3 (2015).

24. A. Kao, B. Cai, P.D. Lee, and K. Pericleous, J. Cryst. Growth 457, 270 (2017).

25. H. Yasuda, K. Inoue, Y. Minami, T. Nagira, M. Yoshiya, K. Uesugi, and K. Umetani, J. Iron. Steel Res. Int. 19S, 34 (2012).

26. P. Lehmann, R. Moreau, D. Camel, and R. Bolcato, Acta Mater. 46, 4067 (1998).

27. A. Bogno, H. Nguyen-Thi, A. Buffet, G. Reinhart, B. Billia, N. Mangelinck-Noël, N. Bergeon, J. Baruchel, and T. Schenk, Acta Mater. 59, 4356 (2011).

28. T. Alboussiere, R. Moreau, and D. Camel, $C$ R Académie des Sciences 313, 749 (1991).

29. D. Du, Y. Fautrelle, Z.M. Ren, R. Moreau, and X. Li, ISIJ Int. 57, 833 (2017). 